\title{
Integrating activity-based travel-demand models with land-use and other long-term lifestyle decisions
}

\author{
Inbal Glickman \\ Technion-Israel Institute of Technology \\ inbal@technion.ac.il \\ Rachel Katoshevski-Cavari \\ Ben-Gurios University of the Negev \\ krachel@post.bgu.ac.il
}

\author{
Robert Ishaq \\ Technion-Israel Institute of Technology \\ roberti@technion.ac.il \\ Yoram Shiftan \\ Technion-Israel Institute of Technology \\ shiftan@technion.ac.il
}

\begin{abstract}
This paper extends and integrates the general activity-based model framework to present the complex relationship between longterm individual decisions, such as residential location, and daily activity and travel-behavior decisions. More specifically, it demonstrates the use of an activity-based accessibility (ABA) measure as an important variable in residential zone choice, thus serving as the link between short-term activity and travel decisions and long-term residential choice decisions. We develop a partial activity-based model accounting for the interrelationship of the main activity type, travel destination and mode choice. The log-sum at the top of the hierarchy of this model is the ABA measure capturing the overall utility of all travel alternatives. The results show that this measure is a highly significant variable in the residential-choice model, clearly indicating the great influence of activity accessibility, short-term opportunities, and travel decisions on residential area choice. All other log-sums were also significant, showing the interrelationships of all choices. Specifically, the destinationchoice log-sum in the main activity-choice model demonstrates that as accessibility increases, people are more likely to participate in out-ofhome activities.
\end{abstract}

Keywords: Activity-based model, land use, urban planning, accessibility

\section{Article history:}

Received: November 30, 2013

Accepted: May 14, 2015

Available online: May 29, 2015

\section{Introduction}

Individual and household activity choices occur over a broad range of timeframes. Activity and travel scheduling involves a selection of activities, sequencing, locations, times, and modes of travel, with some of these decisions made at the household level and assigned to its member and some by the individual members. As activities are being carried out, rescheduling occurs in the shortest timeframe, within the day, in response to information, prompting changes to the planned activity and travel schedule. Mobility and lifestyle decisions, such as residential location, employment, automobile ownership, and activity

Copyright 2015 Inbal Glickman, Robert Ishaq, Rachel Katoshevski-Cavari, \& Yoram Shiftan.

http://dx.doi.org/10.5198/jtlu.2015.658

ISSN: 1938-7849 | Licensed under the Creative Commons Attribution - Noncommercial License 3.0

The Journal of Transport and Land Use is the official journal of the World Society for Transport and Land Use (WSTLUR) and is published and sponsored by the University of Minnesota Center for Transportation Studies. This paper is also published with sponsorship from WSTLUR and the Institutes of Transportation Studies at the University of California, Davis, and the University of California, Berkeley. 
participation, which are more fundamental decisions, influence everyday activity participation. These mobility and lifestyle decisions occur at irregular and infrequent intervals, in a timeframe of years. Miller (2005) argued that long-term decisions are key decisions that influence the spatial context of household members and the long-term ability to travel. These two decision processes, short- and long-term, are bound together. In his opinion, the key difference between them is that short-run decisions involve a fixed set of resources and constraints (e.g., the current fleet of household vehicles, the current job and home), whereas long-run decisions act to change the household's current resources or constraints (e.g., purchasing or selling a car, moving to a new house). Roorda, Carrasco, and Miller (2009) claim that understanding the reasons for a household's car ownership provides the basis for designing a planning policy that will reduce travel time as well as car ownership. Van Acker and Witlox (2010), in a theoretical discussion, posit that short-term activity decisions are made by the individual to satisfy his or her lifestyle decision. They emphasize the importance of long-term decisions in the process of shaping lifestyle.

Activity-based modeling treats travel as being driven by the demand for personal activities. These models predict which activities will be conducted, where, when, and for how long, in addition to such travel characteristics as mode choice, length of travel, and with whom. Consequently, travel choices in these models are part of a broader activity-scheduling process that is based on modeling the demand for activities rather than merely trips and that take into account individual time and space constraints. Hence, these models capture the whole picture of an individual's activities and are able to account for trade-offs among various activities and travel alternatives in one's daily activity pattern. Such models were applied in a range of variations in different studies to model behavioral responses to various policies; for example, by Kitamura et al. 1996; Rossi and Shiftan,1997; Gunn and Van der Hoorn 1998; Shiftan 1999; Algers and Beser 2000; Arentze and Timmermans 2000, 2004; Shiftan and Suhrbier 2002; Katoshevski-Cavari 2007; and Katoshevski-Cavari, Arentze, and Timmermans 2009. However, relatively few studies have applied the activity-based framework to investigate relationships between various long-term individual decisions, such as residential and work location, auto ownership, transitpass holding, and one's daily activity patterns. An example of the importance of understanding these interrelationships for policy planning is the common hypothesis, supported by numerous studies, that such policies encourage higher-density residential areas, mixed land use, transit accessibility, and pedestrian friendliness, thereby creating an environment in which people drive less (Cervero 1989). In other words, these policies can result in reduced motorized travel. Cervero and Kockelman (1997), Newman and Kenworthy (1989, 1999), Holtzclaw (1990), Frank and Pivo (1994), Kitamura, Mokhtarian, and Laidet (1997), Badoe and Miller (2000), and Roodra, Carrasco, and Miller (2009) are examples of studies that assume that living in higher-density neighborhoods contributes to the reduction of the motorized level. These assumptions have led some regions to try to implement such policies as transit-oriented development, mixed land use, and different concentration schemes. (For a review of empirical studies of these policies and their effect on transportation, see among others Bagley and Mokhtarian 2000.) However, there are also studies pointing to no or little influence of the built environment on travel behavior (Handy 1996; Kitamura, Mokhtarian, and Laidet 1997; Boarnet and Sarmineto 1998; Crane and Crepeau 1998). Doubt exists as to whether land-use configuration itself affects travel patterns or whether people with different travel-behavior preferences select different types of neighborhoods, what is often referred to as "self-selective" (see, for example, Dunphy and Fisher 1996).

In this paper, we claim that activity-based travel behavior models should be integrated with longterm decisions, such as residential and work location, to better understand the potential effect of different planning (and transportation) policies. Accordingly, the main objective of this research is to extend and integrate the general activity-based model framework to present the complex relationship between long-term individual decisions, such as residential location, and one's daily activity and travel-behavior 
decisions. More specifically, we demonstrate the use of the activity-based accessibility (ABA) measure as an important variable in residential zone choice, thus serving as the link between short-term activity and travel decisions, on the one hand, and long-term residential choice decisions, on the other. The proposed methodological framework extension enables planners to gain a better understanding of people's activity patterns and spatial decisions as well as to suggest relevant planning policies. The focus is on the Random Utility Model (RUM) approach and the estimation of a full set of log-sums to better test these relationships. Since this is a complicated task in itself, it was necessary to neglect some other complications. Our intention was not to provide a new, full, operational framework for integrating short-term activity and travel-related choices with long-term choices that would account for all the behavioral complexities involved; it was, rather, to demonstrate the improved linkage between these two types of decisions by means of ABA measures that can later be implemented in a broader integrated framework. Such an improved integrated framework, requiring much more research, is beyond the scope of this or any other single paper. We recommend some steps toward such a framework in the section on future research.

The next section first presents related work involving long-term decisions and related methodological issues. Section 3 describes the methodology, including the background of the relevant modeling. Section 4 presents the frame of the work, and Section 5 the analysis of the data. The results of the modeling are discussed with respect to various aspects in Section 6. Overall conclusions are reported in Section 7.

\section{$2 \quad$ Related work}

Ben-Akiva and Bowman (1998) and Shiftan (2008) are two studies that integrate short- and long-term decisions and include in their framework some planning policies that influence long-term decisions. Another example is Miller and colleagues (Miller et al. 2004; Salvini and Miller 2005; Hatzopoulou and Miller 2009), which develop an integrated land-use transportation framework, ILUTE (Integrated Land-use Transportation Environment), that aimed at simulating the effect of different planning policies. Part of the ILUTE model is the Travel Activity Scheduler for Households and Agents (TASHA) an agent-based, micro-simulation framework that merges models of long-run decisions, in this case only decisions concerning vehicle ownership, and short-run mode-choice decision-making. Initial efforts to implement integrated land-use and activity-based travel-demand models are shown by Dong et al. (2006) and Ettema et al. (2006). An example of the partial integration of long-term decisions with travel behavior is presented by Roorda, Carrasco, and Miller (2009), whose model integrated vehicle transactions, activity scheduling, and mode choice. Roorda and Ruiz (2008) studied the dynamically changing behavior of activity scheduling, or the possibility of identifying activity/travel similarities and differences in both short- and long-term activity scheduling. They used the Toronto Travel Activity Panel Survey (TTAPS), an activity diary survey that includes information on people's activities at certain points along a three-year period, and hence allows within-week dynamics to be explored and compared with the yearto-year dynamics of activity/travel behavior. Their focus and conclusions were on understanding the differences/similarities between activity scheduling on different days of the week and activity scheduling on the same day in different years.

An important step in using activity-based travel models to analyze land-use and other long-term policies is the development of activity-based measures of accessibility. Spatial accessibility is the key to connecting travel-related decisions and location decisions, including residential location and workplace. Some previous studies have found accessibility to have in general modestly positive explanatory variables (Blijie 2005; Zondag and Pieters 2005), but their impacts on residential choice behavior are secondary to and confounded by their household, dwelling, and neighborhood characteristics (Waddell 1996; Weisbrod, Lerman, Ben-Akiva 1980). However, Lee et al. (2010) confirm that accessibility remains an important influence on residential choice. They claim that various studies that ignore household 
preferences for access to non-work facilities represent incomplete views of housing-choice decisions, thus emphasizing the need to use accessibility measures for all activities when studying decision-making concerning residential preferences.

The activity-based accessibility (ABA) reflects the expected maximum utility from the activitybased model. It represents the person's access to various activities in order to study how this knowledge affects longer-term land-use variables, such as residential and workplace choices. The ABA measure, first presented by Ben-Akiva and Bowman (1998), makes use of activity-based models and measures the accessibility of all activities in which an individual is engaged, incorporating such constraints as scheduling and such travel characteristics as trip chaining. Integrating the activity-based travel-demand model developed for Boston, with a residential-choice model, the study defined accessibility as the expected value of an individual's maximum utility among the available activity schedules, given a residential location. This definition allows one residential location to have different accessibilities for different people, depending on their characteristics. By considering activity scheduling instead of trips, this measure accommodates individuals' desires to participate in a variety of activities, to combine activities through trip chaining and to gain satisfaction from activities without the need to travel.

Dong et al. (2006), in further developing the ABA measure, defined it similarly to Ben-Akiva and Bowman (1998) and generated it from the day-activity-schedule model. Dong et al. (2006) used the data from Portland to demonstrate the rich picture of accessibility that ABA can generate and its use in analyzing the impact of congestion pricing. They showed how ABA captures taste heterogeneity across individuals; it combines different types of trips into a unified measure of activity, reflecting the impact of scheduling and trip chaining on accessibility and quantifies different accessibility impacts on important segments of the population. A key advantage of ABA is that it treats activities endogenously through a microeconomic approach based on specifying utilities of activity participation; it encompasses activitybased travel choices throughout a whole day schedule, and therefore it covers multiple trips conducted in different time periods of a day. It can reflect the travel time and cost of all travel modes to all destinations on all trips during the day.

Lee et al. (2010) used the time-space prism to study the influence of the accessibility of specific work and non-work activities on residential choice. Using a two-day activity diary from the Puget Sound region council (Seattle, Washington, metropolitan area), they found that after-work activities could have an important role in accessibility consideration for residential location.

ABA, which is calculated as log-sum variables of the activity travel-behavior model, imposes a major computational complexity on model applications. This is due to the need to calculate the utility of every combination of the many alternatives (of which there can be more than a million in the case of the entire day-activity model; see Bowman and Bradley 2006), starting from the bottom of the structure, going up the tree, and then calculating probabilities on the way back down. As indicated by Bradley et al. (2002), log-sum variables add a great deal of complexity to the process of model application and require much more computer time to run. To reduce this complexity, therefore, it is common in practical applications to make various shortcuts and assumptions, such as the use of aggregate log-sums or the elimination of alternatives with low accessibility likelihood as was done, for example, in the San Francisco and Tel Aviv models. Another approach, taken in the Sacramento model, was to select the assumed conditional outcome through a Monte Carlo draw, using approximate probabilities, instead of calculating the log-sum for all possible conditional outcomes.

In all these simplifications, the amount of computation is reduced either by ignoring differences among decision-makers or by calculating utility for a careful subset or aggregation of the available alternatives (Bowman and Bradley 2006; Lee et al. 2010). However, aggregate log-sums can result in unknown biases that result in model-estimation measurement errors and model-application aggrega- 
tion errors. Therefore, it is of great importance to find the right balance between behavioral realism and model complexity (Shiftan and Ben-Akiva 2011). In this work, we calculate the full set of log-sums but focus on modeling that is partially activity-based to capture the most important choice dimensions. The next section provides details about the methodology.

\section{$3 \quad$ Methodology}

Figure 1 presents the framework for interaction between long-term and short-term decisions as described by Shiftan (2008). As can be seen, decisions such as residential choice or car ownership made at the highest level of the system's hierarchy are highly dependent on one another and affect daily activity patterns. All longer-term decisions are further affected by the accessibility of the various activities in which people participate.

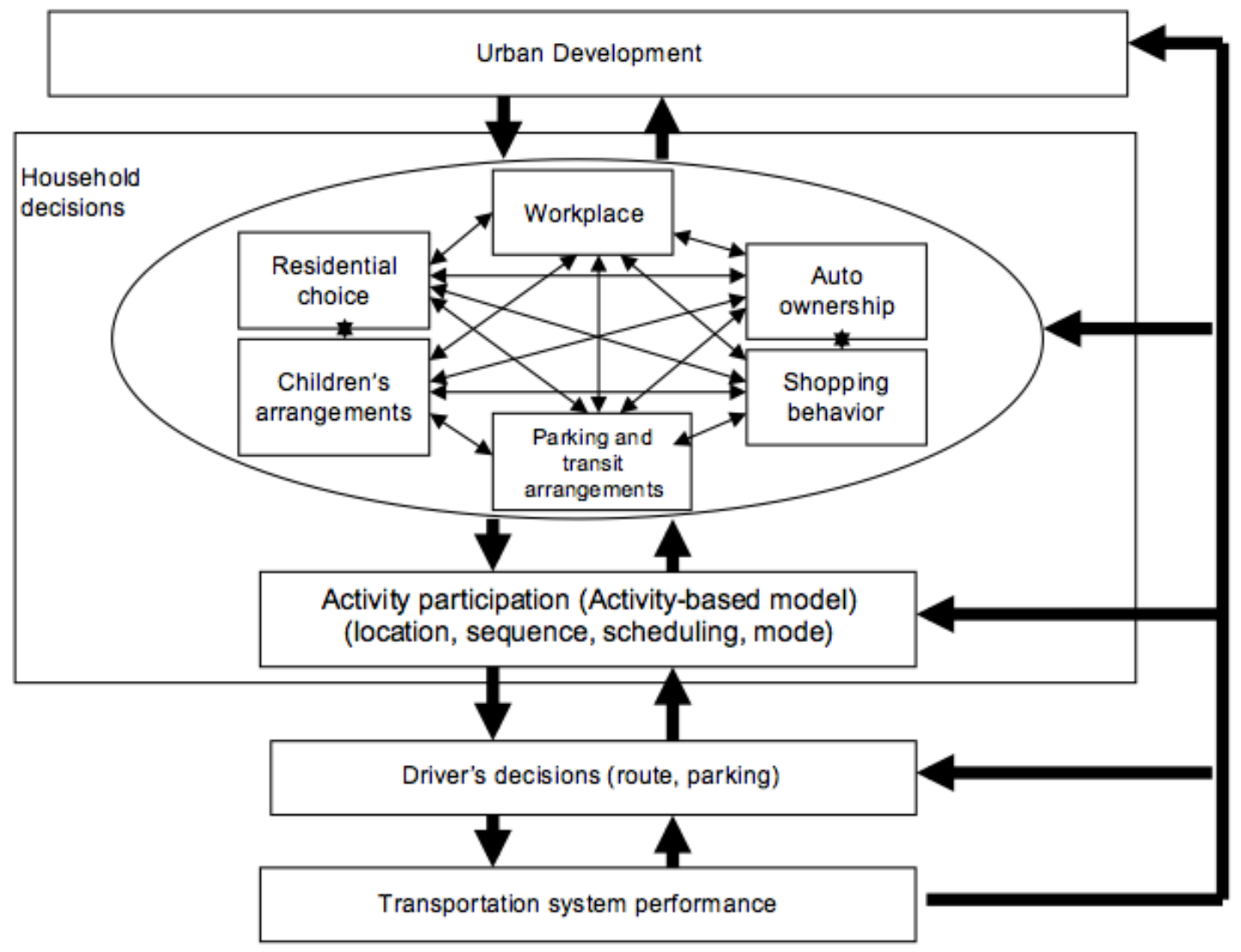

Figure 1: Extended land-use transportation modeling framework 
The model shown in Figure 1 is developed as a system of logit and nested logit models and assumes a hierarchy of components. The model is developed and estimated at the individual level. At the highest level of the activity-based model, a primary activity model determines a person's main activity. If the person has an out-of-home activity, a destination-choice model estimates the zone of this activity. This is followed by a mode-choice model, which estimates the main tour mode for this activity.

A full set of log-sum variables connects all of these sub-models. Although one can argue whether this structure best represents behavior, testing every structure is not feasible within the scope of this study. However, there is sufficient experience with activity-based models to show that the order used here is logical. It was used in Portland (Bowman et al. 1998), San Francisco (Jonnalagadda et al. 1999), Florida (Pendyala, Kitamura, and Kikuchi 2004), Jakarta (Yagi 2006), and Atlanta (Bradly and Vovsha 2005). More importantly, we replicated the structure of the actual Tel-Aviv model, which was estimated with the same data (Tel-Aviv Activity Schedule Travel Demand Model System 2008).

Finally, as our main contribution, we extended this model by adding a residential-choice model to the activity-based accessibility measure. The extended model structure is shown in Figure 2; the upward arrows there reflect the accessibility/log-sum variables, providing information from lower-level to upperlevel model.

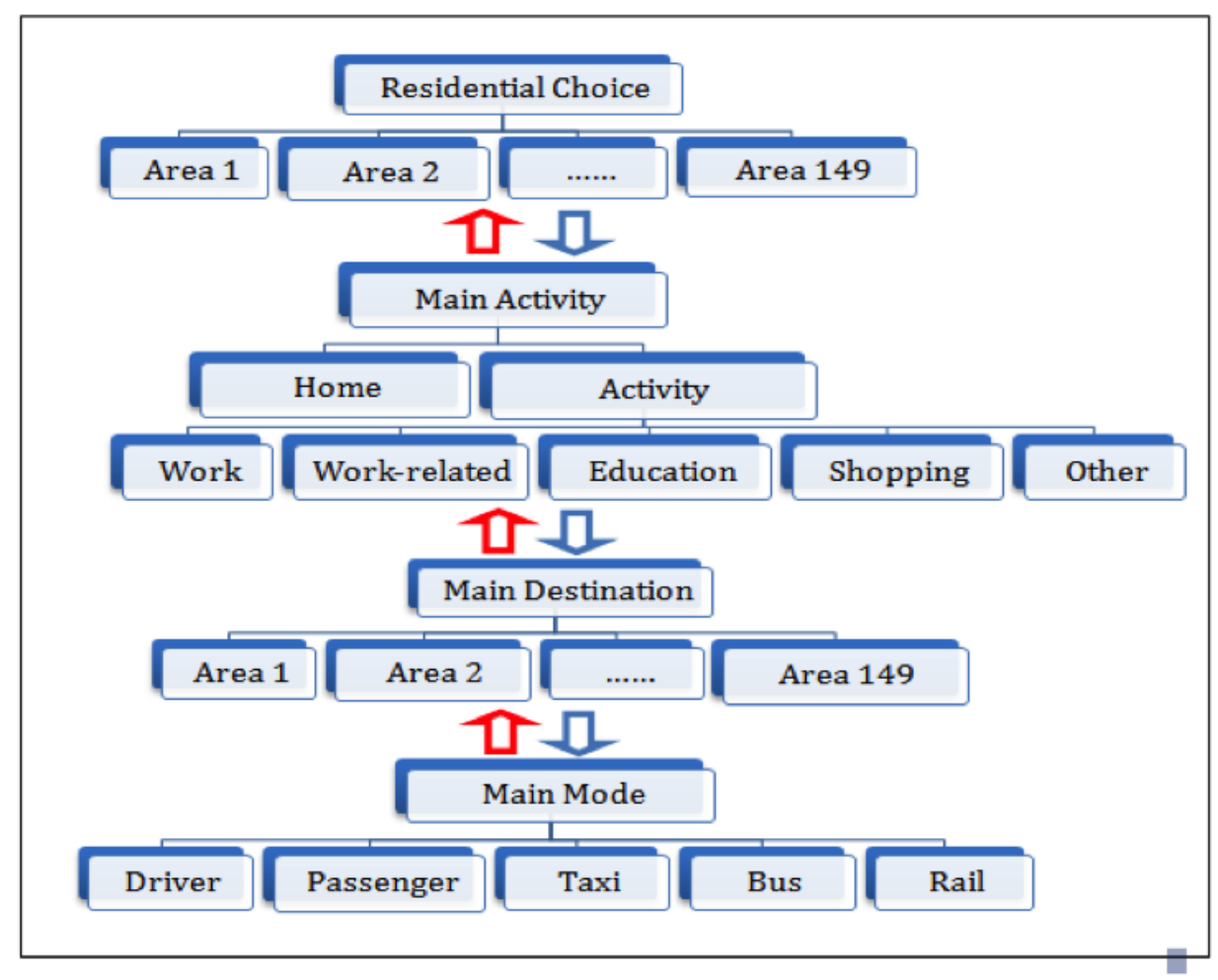

Figure 2: Extended model structure

All the (sub) models in this study were estimated using a discrete-choice model comprising three multinomial models: mode choice, destination choice, and residential choice; the main activity choice is a nested logit model.

The residential-choice model that we chose for demonstrating the multinomial model used in this study estimates the probability of an individual residing in each traffic zone in the metropolitan area. Ideally, residential choice should be modeled as a household decision based on a two-stage process, in which 
a group of zones is first defined to create a smaller set of areas from which to choose in the second/final stage. However, as part of the simplification necessary for the present work, as mentioned above, residential choice was modeled at the individual level, using a one-stage multinomial logit (MNL) model.

For both spatial models, the residential location model and the main-activity destination-choice model, we aggregated the 1200 traffic analysis zones in the Tel-Aviv metropolitan area into 149 super zones.

The residential-choice model is a multinomial logit (MNL) in which the utility of each residential location is specified as:

$$
U_{i}=V_{i}+\varepsilon_{i}
$$

Where $U_{i}$ is the utility of residential alternative $i$ for a given household; $V_{i}$ is the systematic component; and $\varepsilon_{i}$ is a random component.

The systematic component of the utility can be written as:

$$
V_{i}=\beta^{\prime} X_{i}
$$

Where $X_{i}$ is a vector of attributes for alternative $\mathrm{i}$, some of which interact with household characteristics; and $\beta$ is a vector of coefficients.

One of the variables in this model is the log-sum variable from the activity model, representing the overall accessibility of the zone for the individual.

In the MNL model, $\varepsilon_{i}$ is Gumbel-distributed independently and identically across alternatives. The probability that alternative $i$ will be chosen is:

$$
p(i)=\frac{\exp \left(\mu V_{i}\right)}{\sum \exp \left(\mu V_{i}\right)}
$$

Where $\mu$ is the scale parameter; and $\mathrm{L}$ is the set of available alternatives.

The destination-choice and mode-choice models are also multinomial logit models using the same scheme.

The main activity model is a nested logit model. At the upper level of the nest, the model estimates the probability of staying home versus conducting an activity out of home. If the person conducts an out-of-home activity, the lower level of the nest estimates the probability of this main activity being work, work-related, education, shopping, or other. The process of defining "main activity" in the model is described later in the paper, where we discuss the results of the main-activity-choice model.

$$
P_{i}=\frac{\frac{V_{i}}{e^{\lambda_{k}}}\left(\sum_{j=B_{i}}^{\frac{V_{j}}{e^{\lambda_{l}}}}\right)^{\lambda_{k}-1}}{\sum_{l=I}^{K}\left(\sum_{j=B_{l}}^{\frac{V_{j}}{e^{\lambda_{l}}}}\right)^{\lambda_{l}}}
$$

Where parameter $\lambda_{k}$ measures the degree of independence of unobserved factors among the alternatives in the same nest $k$. 
The log-sum, which is the log of the denominator of the logit choice probability, provides the expected value of the individual's maximum utility, given the choice situation. With a full set of log-sums connecting all lower-level decision models to their corresponding higher-level decision models, the logsum obtained at the very top of the hierarchy is a "top" accessibility measure, the ABA measure, which captures the overall utility of all travel alternatives for the various dimensions, such as destination, mode, time, and travel patterns.

\section{The study frame}

We will now present a case study of the Tel-Aviv metropolitan area (Map 1). Tel Aviv, located along the Mediterranean coastline, is the largest metropolitan area in Israel and serves as the country's main financial and cultural center. It has 3.5 million residents, composing about 42 percent of Israel's population.

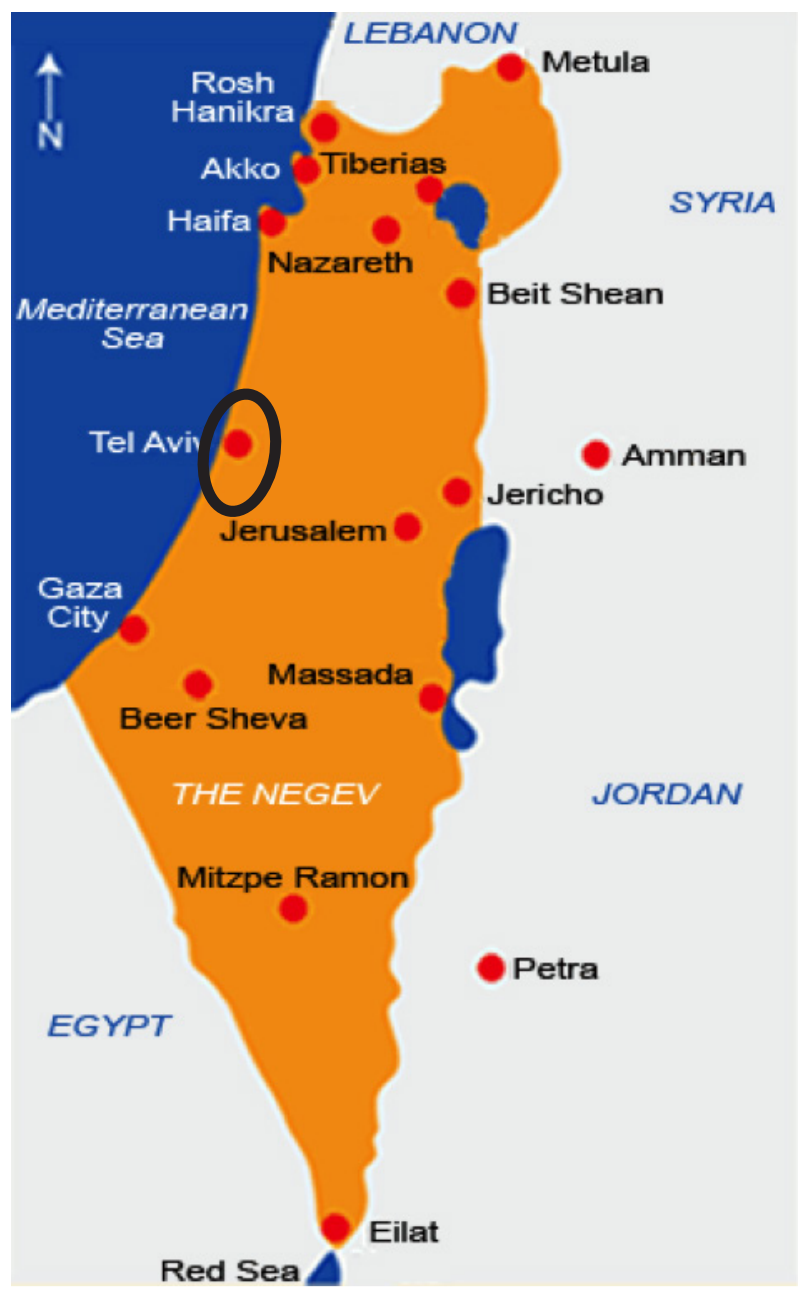

Map 1: Map of Israel, the Tel-Aviv metropolitan area shown schematically in the ellipse

The study is based on the same data that was used to estimate the Tel-Aviv activity- based model. However, to simplify and make the activity-based model more practical (in aspects of complexity and computer run-time), the Tel-Aviv model includes only a partial set of log-sums (Shiftan and Ben-Akiva 2011). Because of the lack of a full set of log-sum variables among all components in the Tel-Aviv model, we re-estimated a new model representing the main daily activity and travel decisions. To enable the 
estimation and application of a full set of log-sums, the focus is only on the three main decisions: main activity type, main activity destination, and main mode. These do not reflect, of course, the full range of travel choices that appear in the Tel-Aviv activity-based model.

The current study includes daily activity patterns, taken from the national travel-habit survey conducted in 1996-97. That survey includes about 8000 households, in which each household member aged eight and older completed a diary for one to three days. Around 60,000 activity patterns were extracted from this data, and some 40,000 complete daily patterns were used for this study. The survey also included various socioeconomic variables. In addition, matrices of the different levels of service variables for the various modes were added to the data.

\section{$5 \quad$ Data analysis}

This section presents some data regarding various socioeconomic aspects of our sample. Table 1 , containing the main characteristics of the sample, shows that more than 50 percent of the population was in the 28-65 age range, 59 percent of the workers had a full-time job, and 79 percent of the households owned at least one car.

Table 1: Main household and personal characteristics of the sample

\begin{tabular}{|c|l|}
\hline Characteristic & \multicolumn{1}{c|}{ Observations } \\
\hline Age & $\begin{array}{l}\text { 21 percent are less than 22 years old, 14 percent are age 22-28, 57 percent } \\
\text { age 28-65, and 8 percent are older than 65 }\end{array}$ \\
\hline Work Status & $\begin{array}{l}59 \text { percent are full-time workers, 1 percent work part-time, 2 percent are } \\
\text { soldiers, 25 percent are unemployed, and 13 percent did not answer }\end{array}$ \\
\hline Car Ownership & $\begin{array}{l}21 \text { percent have no vehicles, 45 percent own one vehicle, 28 percent own } \\
\text { two vehicles, and 6 percent indicated having three or more vehicles }\end{array}$ \\
\hline
\end{tabular}

Figures 3-9 describe some basic relationships among the different relevant variables. As can be seen in Figure 3, the distribution of mode by gender, men drive more than women, and women use the bus or ride as passengers more than men. In Figure 4, the distribution of mode by activity, the car is the mode most used for work activities; it is also highly used for shopping, work-related activities, and other activities. The most common mode for education activity is the car, but as a passenger. Figure 5 shows the distribution of the locations of the main activities by geographical rings (see Map 2) and by activity purpose. The third ring is the largest in terms of residence and workplaces, followed by the second ring, the division coinciding with the geographical size of the area. The distribution of residents and workplaces in each of the rings shows that there are more workplaces than residential locations in the central business district (CBD), while residences predominate in the two outer rings.

When looking at the main destination by main activity, one sees (Figure 6) that home and education activities are more common in the third ring, while work activities are more common in the CBD. Figure 7, presenting the distribution of main activities by number of children, indicates a very similar distribution for work-related, education, and shopping activities as the main activities for households having one to three children. Differences are found for households with four children or more; working as the main activity is lower, and education activities are higher. No significant differences were found in main activities with the increase in the number of vehicles per household; however, for households having no vehicle, working as the main activity was less common (Figure 8). As expected, work activity as the main activity for full-time workers is very high (56 percent) and drops considerably for part-time workers (22 percent) (Figure 9). Soldiers in the Israeli context have different activity patterns than do full-time workers, as the former remain mainly on the army base for most of the week and even during 
some of the weekends. Table 2 indicates that as the household becomes larger, it tends less to live in the $\mathrm{CBD}$ and more in the second ring; and with the increase in the number of vehicles, households tend to live more in the third ring.

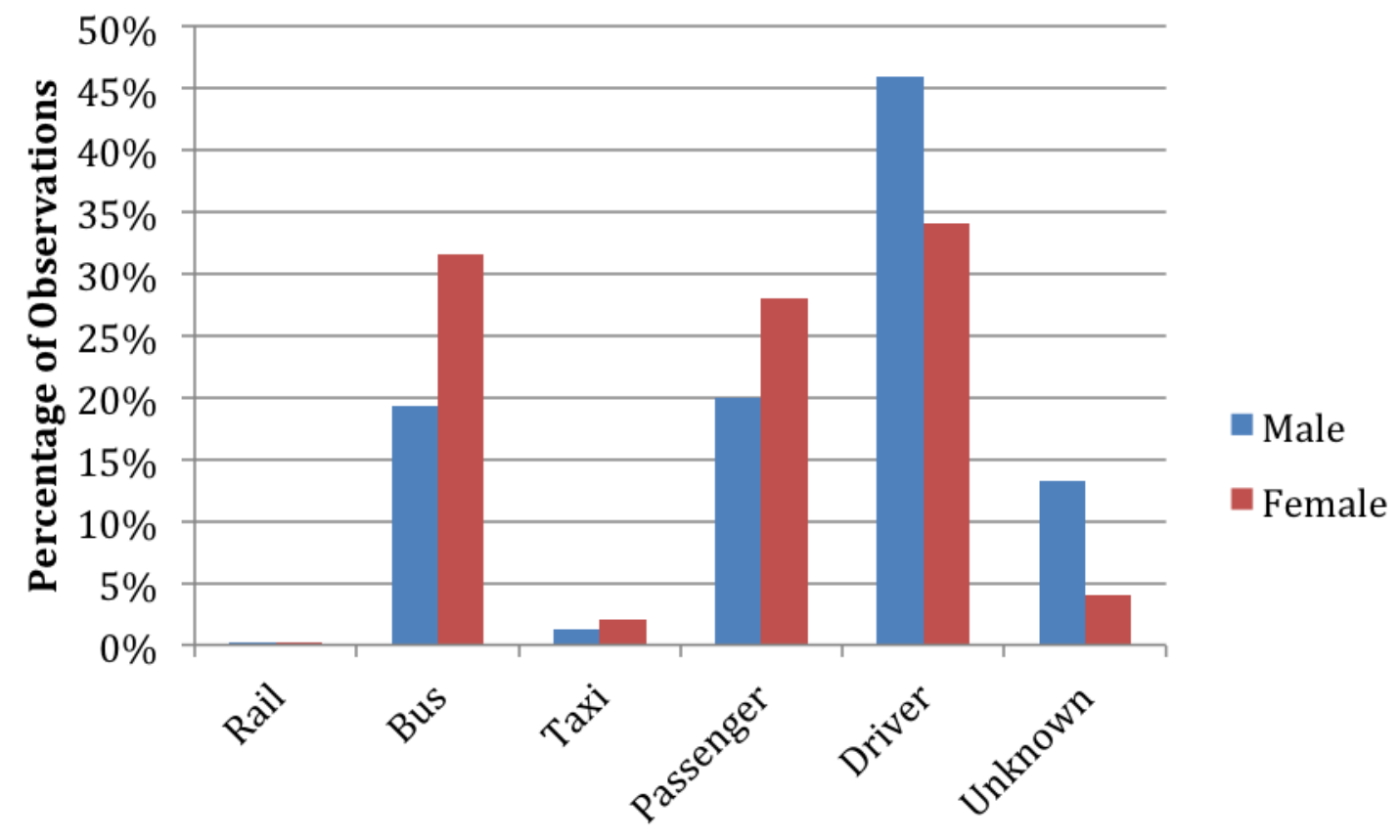

Main Transport Mode

Figure 3: Main mode of transportation by gender

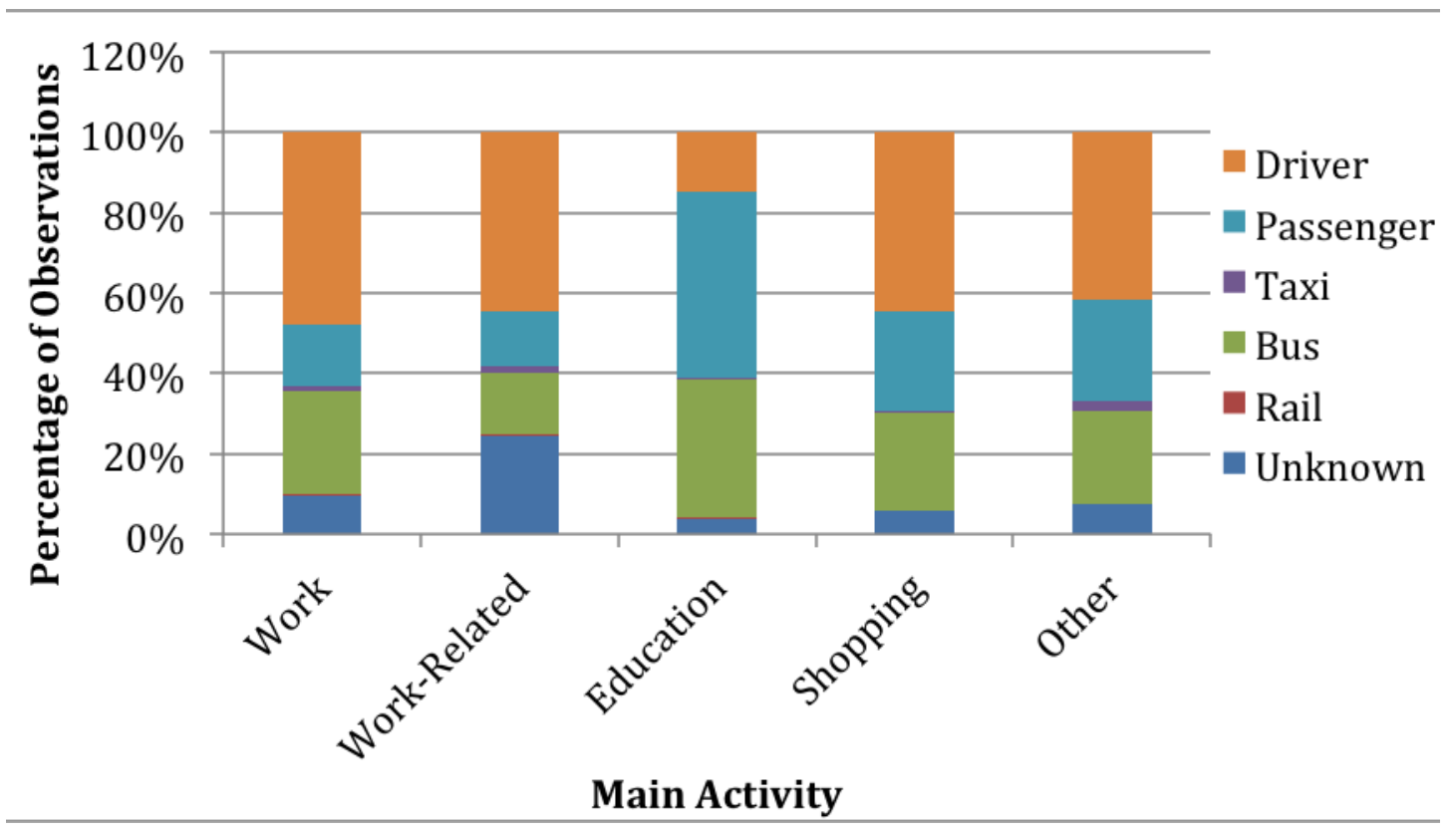

Figure 4: Main mode of transportation by main activity 


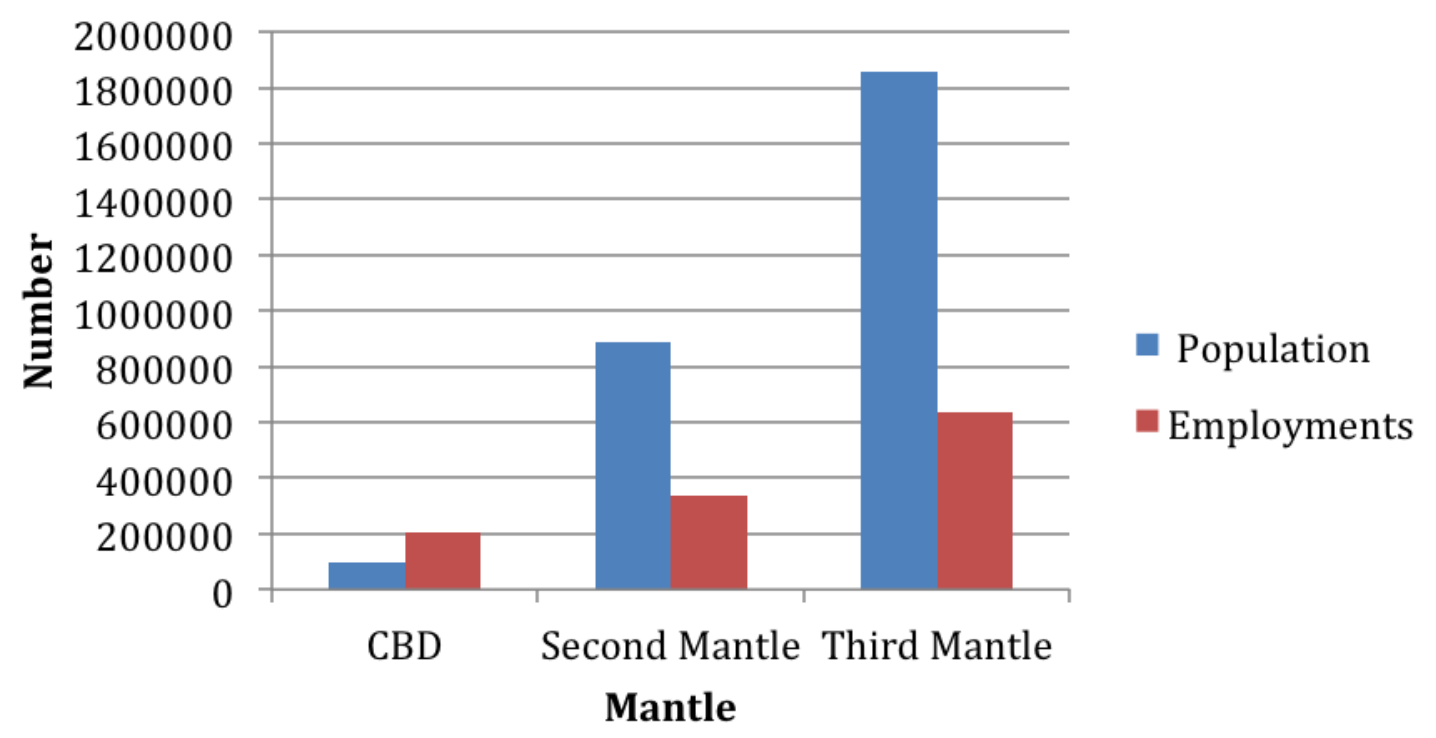

Figure 5: Distribution of population and employment by geographical ring

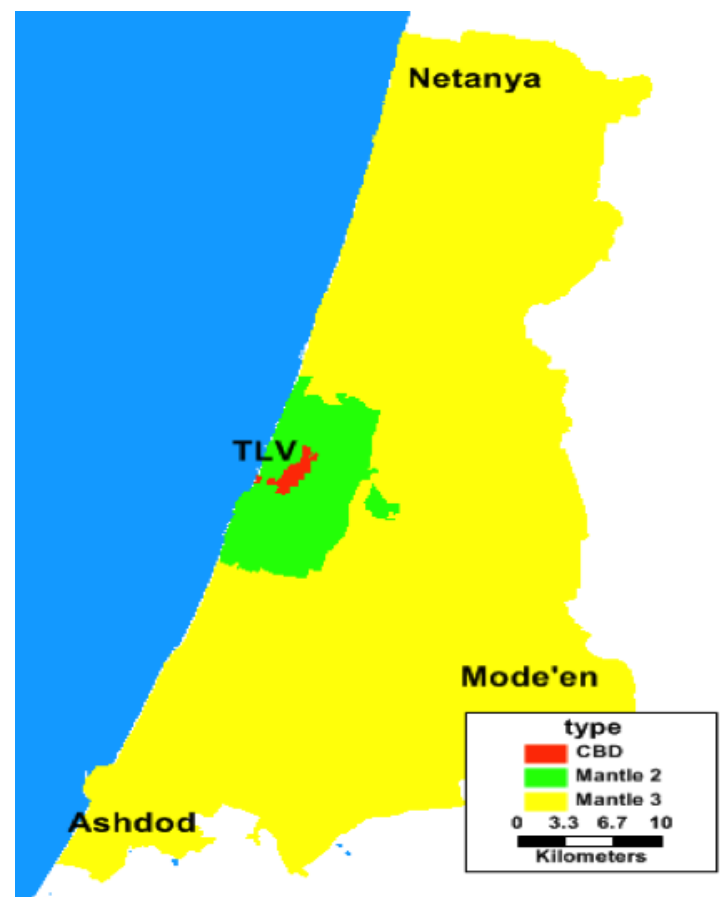

Map 2: Mantles map of the Tel-Aviv metropolitan area 


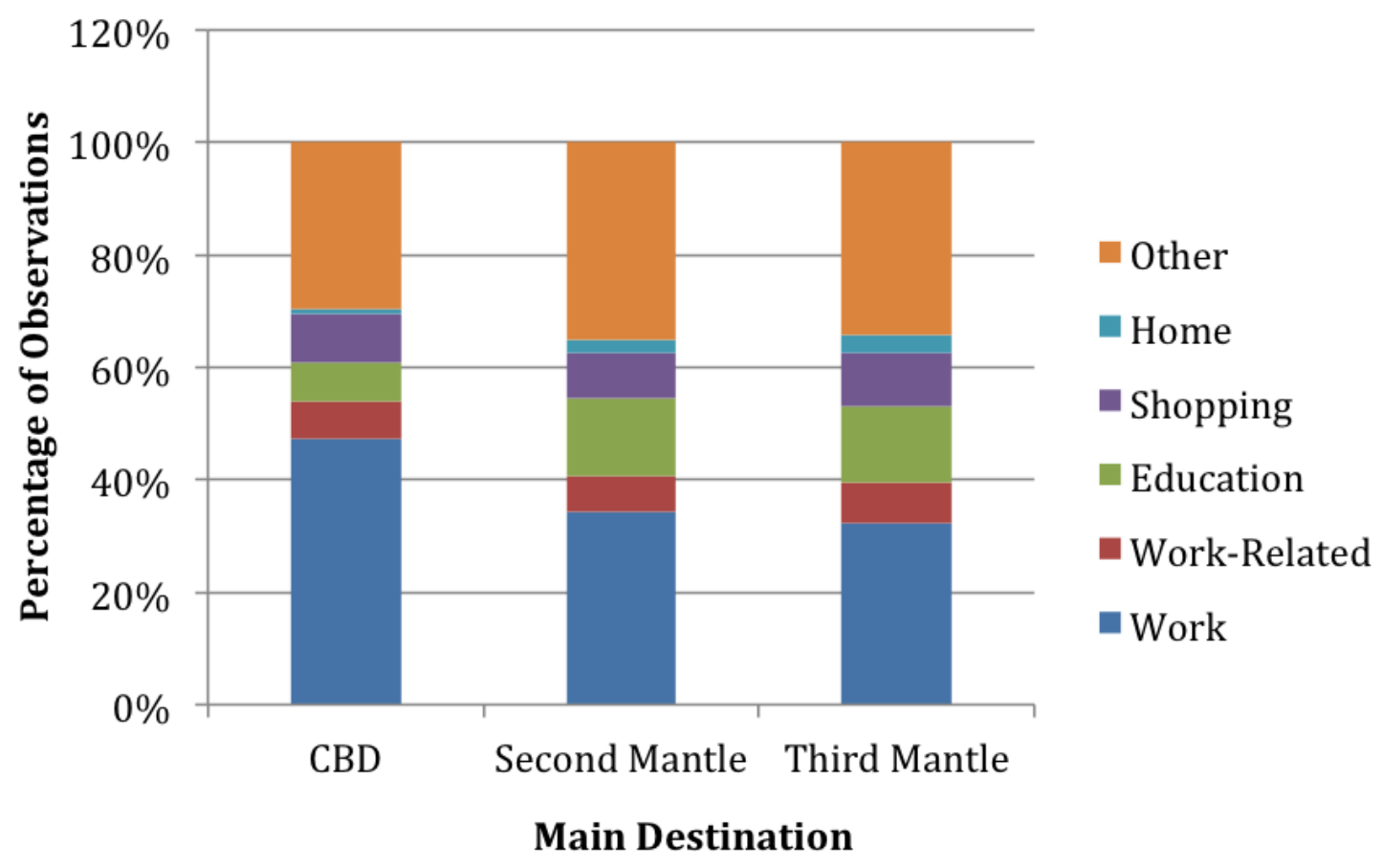

Figure 6: Main activity by main destination

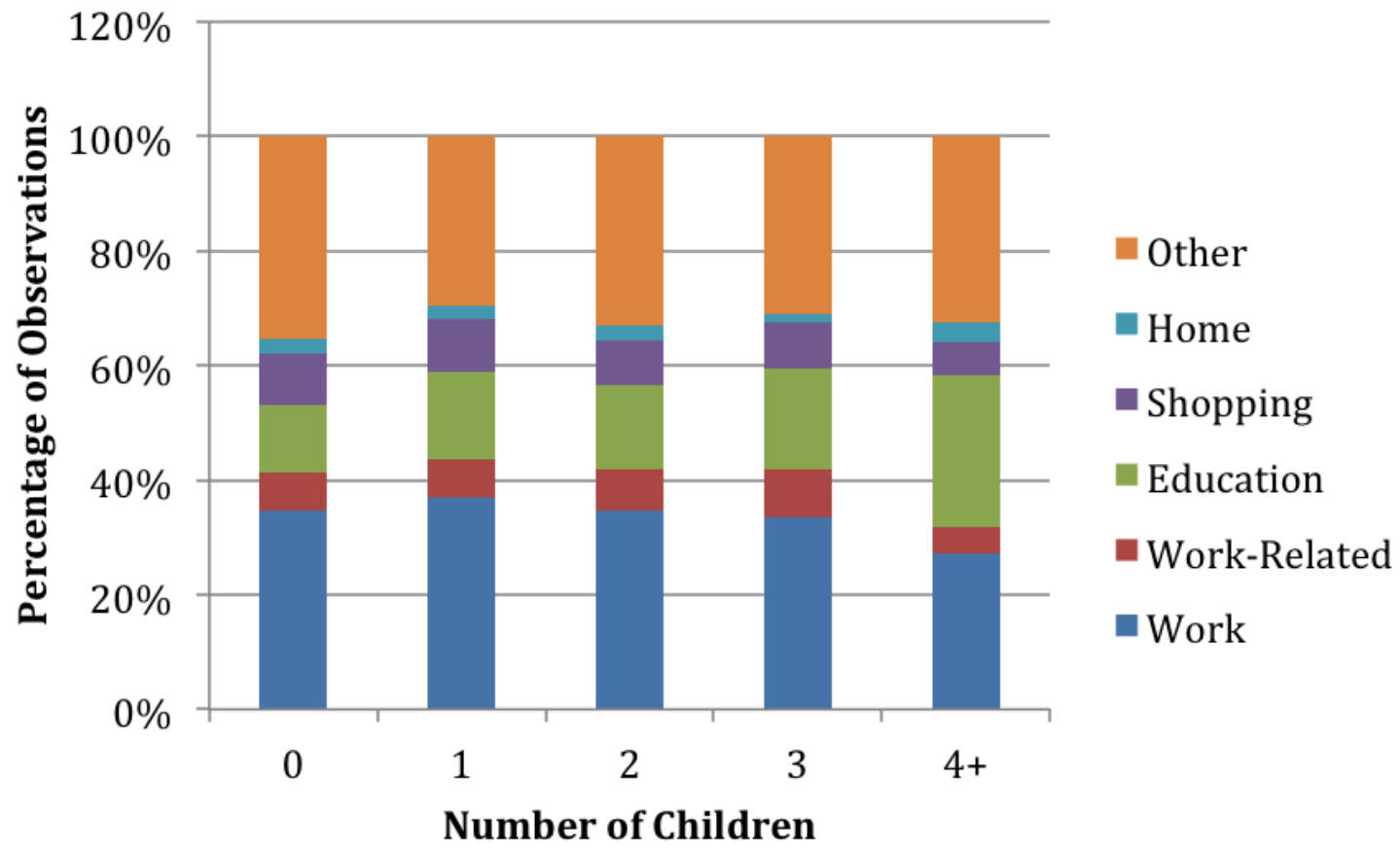

Figure 7: Main activity by number of children 


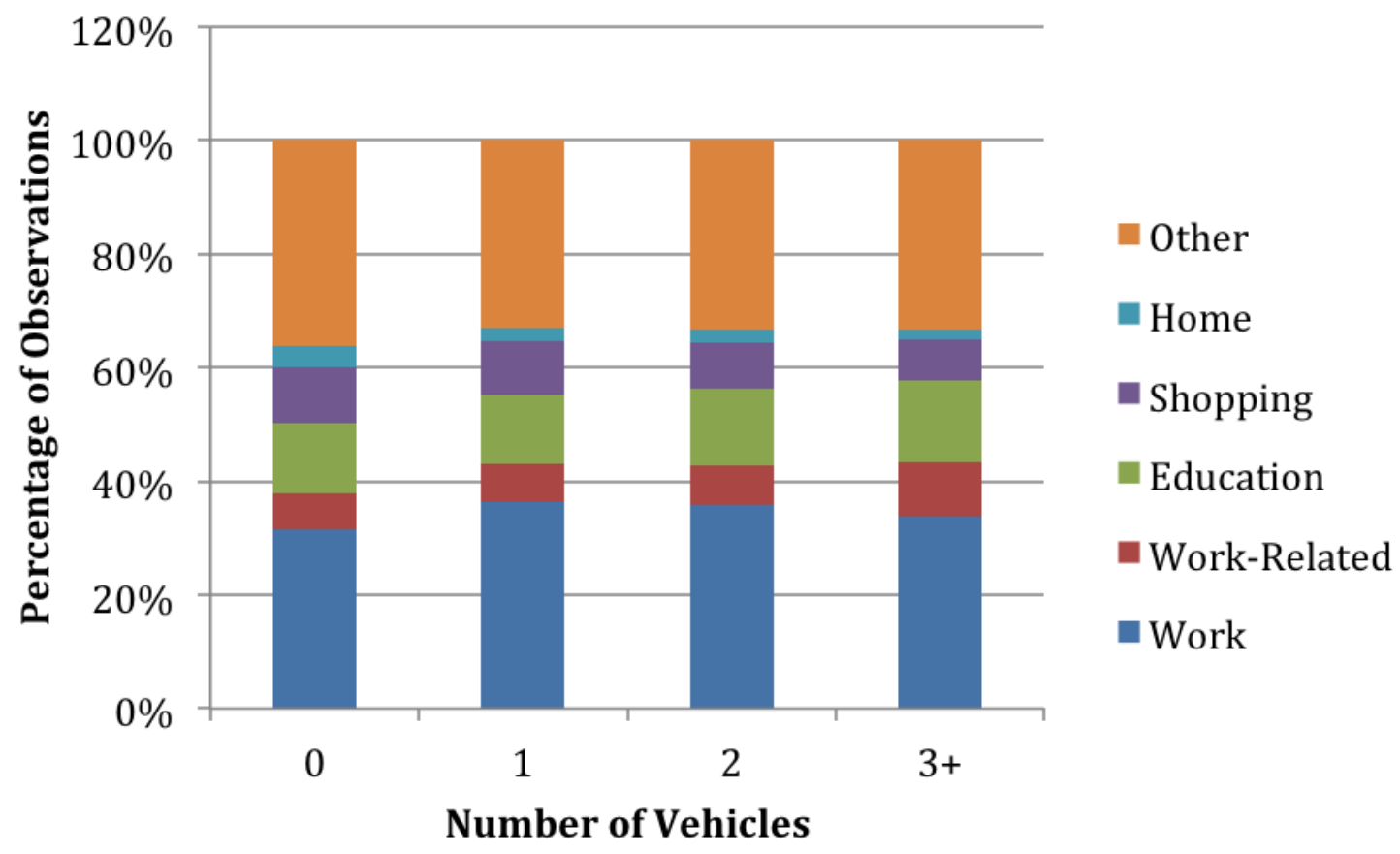

Figure 8: Main activity by number of vehicles in household

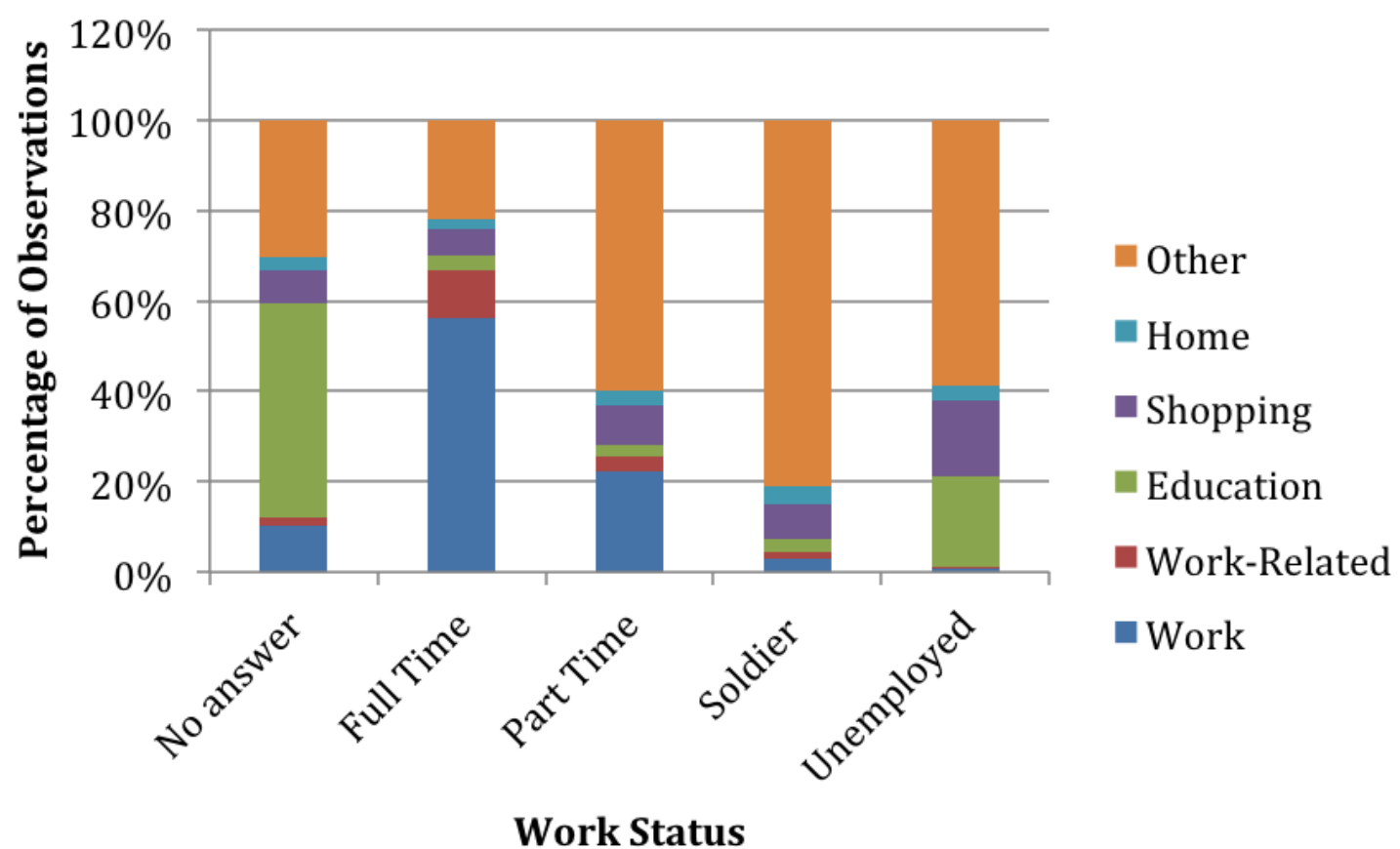

Figure 9: Main activity by work status 
Table 2: Home area by vehicle ownership and by number of children

\begin{tabular}{|c|c|c|c|}
\hline Household Characteristic & \multicolumn{3}{|c|}{ Home Area } \\
\hline Number of Vehicles & CBD & Second Mantle & Third Mantle \\
\hline 0 & $4 \%$ & $44 \%$ & $52 \%$ \\
\hline 1 & $3 \%$ & $34 \%$ & $62 \%$ \\
\hline 2 & $4 \%$ & $28 \%$ & $68 \%$ \\
\hline $3+$ & $4 \%$ & $27 \%$ & $69 \%$ \\
\hline Number of Children & CBD & Second Mantle & Third Mantle \\
\hline 0 & $4 \%$ & $37 \%$ & $58 \%$ \\
\hline 1 & $2 \%$ & $27 \%$ & $71 \%$ \\
\hline 2 & $2 \%$ & $27 \%$ & $71 \%$ \\
\hline 3 & $2 \%$ & $34 \%$ & $64 \%$ \\
\hline $4+$ & $0 \%$ & $55 \%$ & $45 \%$ \\
\hline
\end{tabular}

\section{$6 \quad$ Model estimation results}

This section describes all the modeling results, starting with the two travel-related models, mode choice and destination choice, followed by the main-activity-choice model, and finally the residential-choice model. As described above, each model includes a log-sum variable representing the accessibility obtained from the lower- level decision dimension. For example, the destination-choice model includes the log-sum from the mode-choice model, representing the accessibility of each destination by all available modes.

\subsection{Main-mode choice}

This model estimates the probability of each of the five modes included in the study being chosen as the main mode of the tour. Main mode is defined as the mode taken for the first trip out of the home. In more than 90 percent of the cases, this was the mode that served all trip segments of the tour. The full Tel-Aviv model contains an additional model, not employed here, estimating whether the individual switches mode during the tour, and to which mode. The five alternative modes are as follows: private car as a driver, private car as a passenger, taxi, bus, and train. The Tel-Aviv survey did not include data about tours performed by walking and biking.

The main mode of the tours was distributed as follows: 40 percent by private car as driver, 24 percent by private car as passenger, 25 percent by bus, 2 percent by taxi, 2 percent by rail, and 7 percent unknown. Table 3 presents the model estimation results. The numbers in the table are parameter coefficients, and the numbers in brackets are the t-test.

As expected, the results show that the number of cars in the household is a very strong determinant of car choice. That is, when there are more cars in the household, the individual is significantly more likely to drive. In addition, this person is also more likely to be a car or rail passenger, but is less likely to order a taxi and is least likely to ride the bus. These results point to the fact that rail is used more than bus by people with car availability, bus being used mostly by people with no car available. When there are more children in the household, people are also more likely to use a car, more as a passenger, then followed as a driver; these people tend to travel less by taxi and least by public transport.

The results also show that people in the age range of 28 to 65 are more likely to drive than to use 
any other mode. Level-of-service variables, time, and cost were found to be highly significant and to show that travel time and travel cost have a negative influence on choosing each mode. The a.m. time parameters of the driver, car passenger, and taxi are close, but they are quite different from those of the rail and bus. This model was significantly better than one constraining all these parameters to be equal and enabled identifying travelers' different values of time (travel preferences) with these different modes.

Table 3: Main-mode-choice model estimation results

\begin{tabular}{|c|c|c|c|c|c|c|c|}
\hline & Constant & A.M. Time & Cost & $\begin{array}{c}\text { Age } 28 \text { to } 65 \\
\text { (dummy) }\end{array}$ & $\begin{array}{l}\text { Gender } \\
\text { (dummy) }\end{array}$ & $\begin{array}{l}\text { No. of } \\
\text { cars }\end{array}$ & $\begin{array}{l}\text { No. of } \\
\text { children }\end{array}$ \\
\hline \multirow{2}{*}{ Driver } & -3.26 & -0.0153 & -0.102 & 1.66 & 1.17 & 1.77 & 0.176 \\
\hline & $(-68.15)$ & $(-13.62)$ & $(-16.48)$ & (50.75) & (38.04) & (77.59) & (9.03) \\
\hline \multirow{2}{*}{ Passenger } & -0.955 & -0.0186 & -0.102 & -0.149 & 0.233 & 0.82 & 0.275 \\
\hline & $(-24.94)$ & $(-16.39)$ & $(-16.48)$ & $(-4.91)$ & $(7.82)$ & $(38.65)$ & (14.36) \\
\hline \multirow{2}{*}{ Taxi } & -3.03 & -0.0173 & -0.102 & 0.368 & & 0.19 & 0.134 \\
\hline & $(-33.15)$ & $(-7.15)$ & $(-16.48)$ & $(4.5)$ & & $(3.23)$ & $(2.65)$ \\
\hline \multirow{2}{*}{ Rail } & -5.76 & -0.00123 & -0.102 & & 0.552 & 0.704 & \\
\hline & $(-21.94)$ & Fixed & $(-16.48)$ & & (2.27) & (4.3) & \\
\hline \multirow{2}{*}{ Bus } & 0 & -0.0062 & -0.102 & & & & \\
\hline & & $(-13.44)$ & $(-16.48)$ & & & & \\
\hline \multicolumn{4}{|c|}{ Number of estimated parameters: } & \multicolumn{4}{|c|}{22} \\
\hline \multicolumn{4}{|c|}{ Number of observations: } & \multicolumn{4}{|c|}{37115} \\
\hline \multicolumn{4}{|c|}{ Null log-likelihood: } & \multicolumn{4}{|c|}{-55286.814} \\
\hline \multicolumn{4}{|c|}{ Final log-likelihood: } & \multicolumn{4}{|c|}{-35044.175} \\
\hline \multicolumn{4}{|c|}{ Likelihood ratio test: } & \multicolumn{4}{|c|}{40485.278} \\
\hline \multicolumn{4}{|c|}{ Rho-square: } & \multicolumn{4}{|c|}{0.366} \\
\hline
\end{tabular}

A.M- time: travel time in each mode (rail/bus/car/taxi) during a.m. peak time. Cost: the travel cost in each mode (rail/bus/car/taxi). Gender: male-1, female-0. Age 28-65 years old: yes-1, no-0. No. of cars: number of cars in household. No. of children: number of children in household.

\subsection{Main-destination choice}

This model estimates the probability of each of the 149 super zones being chosen as the destination for the main activity. The distribution of the main destination was as follows: 14 percent of the respondents chose the CBD, 32 percent the second mantle, and 54 percent the third mantle. Variables of zonal characteristics were included in addition to travel time. The model also includes the log-sum from the tour main-mode-choice model as a variable, representing location accessibility. Equation 5 shows the calculation of this log-sum. Table 4 shows the model estimation results; the numbers in the table are parameter coefficients, and those in brackets are the t-test values.

As expected, the results indicate that, in relative terms (size of the area/mantle), high employment-density areas in the CBD are most likely to be chosen as the main destination. That is, people tend to choose a commercial/business type of area for their main destination. This finding coincides with the results showing that a residential area with higher population density is less attractive as a dwelling area. Travel time, as expected, is negative, proving that closer destinations are more attractive. The results signify that the log-sum variable from the main-mode-choice model is also highly significant, showing that zones with higher accessibility are more likely to be chosen. Finally, the size variable, lnPop, is also significant, meaning that larger zones in terms of population are more likely to 
be chosen as the main destination.

LogsumFromMainMode $=\operatorname{Ln}\left(e^{\text {Vdriver }}+e^{\text {Vpassenger }}+e^{\text {Vtaxi }}+e^{\text {Vrail }}+e^{\text {Vbus }}\right)$

Table 4: Main-destination-choice model estimation results

\begin{tabular}{|l|c|c|c|c|c|c|}
\hline & PopDens & EmpDens & ActCarTime & InPop & IsCBD & $\begin{array}{c}\text { Log-sum From } \\
\text { Main Mode }\end{array}$ \\
\hline Area & -0.0000281 & 0.000033 & -0.0417 & 0.414 & 0.401 & 1.6 \\
\cline { 2 - 6 } $1-149$ & $(-32.25)$ & $(65.8)$ & $(-53.58)$ & $(57.42)$ & $(18.69)$ & $(77.1)$ \\
\hline \multicolumn{3}{|c|}{ Number of estimated parameters: } & \multicolumn{3}{|c|}{40728} \\
\hline \multicolumn{3}{|l|}{ Number of observations: } & \multicolumn{3}{|c|}{-163800.725} \\
\hline \multicolumn{3}{|l|}{ Init log-likelihood: } & \multicolumn{3}{|c|}{81468.697} \\
\hline \multicolumn{3}{|l|}{ Final log-likelihood: } & \multicolumn{3}{|c|}{0.200} \\
\hline
\end{tabular}

PopDens: population density in each of the 149 zones; EmpDens: employment density in each of the 149 zones; ActCarTime: actual riding time in private car (minutes); InPop: population size in each zone 1-149; IsCBD: is the zone in the CBD? Yes-1, No-2; Log-sum FromMainMode: log-sum from the main-mode-choice model.

\subsection{Main-activity choice}

This nested-logit model estimates the probability of various activities being a person's main activity. At the higher level of the nest, the individual chooses whether to stay home or to perform an activity away from home. At the lower level of the nest, the individual chooses among five out-of-home alternative activities: work, work-related activity, shopping, study, and other. The tour's main activity was defined by observing the individual's activities at each stop of the tour and then identifying the most important activity, based on its purpose and duration. If the tour involved more than one work activity, that with the longest duration was defined as the main activity. Similarly, if the tour had more than one education activity, that with the longest duration was defined as the main activity, etc.

The main activity was distributed as follows: 35 percent work, 7 percent work-related, 13 percent education, 9 percent shopping, 33 percent other, and 9 percent stayed at home. Equation 6 presents the calculation of the log-sum variable, and Table 5 shows the model estimation results. The values in the table are parameter coefficients, and those in brackets are the t-test values.

The results show that men and workers (as opposed to non-workers) are more likely to work and make work-related tours. In addition, men are less likely to make shopping tours. As expected, working people are more likely to choose work as their main activity; however, as the results show, they also participate in more other activities than do non-workers. Car ownership positively influences the choice of all activities (no significant results were found for any one specific activity). People in the 28- to 65-year-old age group tend to do more out-of-home activities than people in the two other age categories. Individuals in households with more children are more likely to choose study and shopping as the main activity than are those in households with fewer or no children.

The log-sum from the main destination, reflecting the overall accessibility of an activity, shows that people are more likely to participate in out-of-home activities as accessibility increases. This result points to one of the main advantages of activity-based models, in which the generation of activities and the resulting trips made to conduct these activities are not fixed; rather, they depend on accessibility options. 
LogsumFromMainDest $=\operatorname{Ln}\left(e^{V 1}+e^{V 2}+\cdots+e^{V 149}\right)$

Table 5: Main-activity-choice model estimation results

\begin{tabular}{|c|c|c|c|c|c|c|c|c|}
\hline & Constant & Gender & Worker & $\begin{array}{l}\text { No. of } \\
\text { cars }\end{array}$ & $\begin{array}{c}\text { Age } 22 \\
\text { to } 28\end{array}$ & $\begin{array}{c}\text { Age more } \\
\text { than } 65\end{array}$ & $\begin{array}{l}\text { No. of } \\
\text { children }\end{array}$ & $\begin{array}{c}\text { Log-sum from } \\
\text { Main Dest }\end{array}$ \\
\hline \multirow[t]{2}{*}{ Work } & 2.71 & 0.0281 & 0.555 & 0.226 & -0.167 & -0.295 & - & 0.0342 \\
\hline & $(21.63)$ & $(3.72)$ & $(4.04)$ & $(5.36)$ & $(-1.84)$ & $(-2.94)$ & - & (1.7) \\
\hline \multirow{2}{*}{$\begin{array}{l}\text { Work- } \\
\text { Related }\end{array}$} & 2.5 & 0.104 & 0.521 & 0.235 & -0.167 & -0.298 & & 0.0342 \\
\hline & $(14.57)$ & $(3.96)$ & $(4.03)$ & $(5.64)$ & $(-1.84)$ & $(-2.96)$ & & $(1.7)$ \\
\hline \multirow{2}{*}{$\begin{array}{l}\text { Educa- } \\
\text { tion }\end{array}$} & 2.88 & - & - & 0.274 & -0.151 & -0.476 & 0.0277 & 0.0342 \\
\hline & $(32.52)$ & - & - & $(6.77)$ & $(-1.68)$ & $(-4.54)$ & $(3.81)$ & $(1.7)$ \\
\hline \multirow[t]{2}{*}{ Shopping } & 2.82 & -0.0365 & 0.193 & 0.255 & -0.174 & -0.191 & 0.0111 & 0.0342 \\
\hline & $(27.96)$ & $(-3.7)$ & $(4.03)$ & $(6.26)$ & $(-1.92)$ & $(-1.79)$ & $(3.4)$ & $(1.7)$ \\
\hline \multirow[t]{2}{*}{ Other } & 2.95 & - & 0.178 & 0.262 & -0.174 & -0.213 & 0.0111 & 0.0342 \\
\hline & $(38.44)$ & - & $(4.04)$ & $(6.45)$ & $(-1.92)$ & $(-2.03)$ & $(3.4)$ & $(1.7)$ \\
\hline Home & 0 & - & - & - & - & - & - & - \\
\hline \multicolumn{5}{|c|}{ Number of estimated parameters: } & \multicolumn{4}{|c|}{29} \\
\hline \multicolumn{5}{|c|}{ Final log-likelihood: } & \multicolumn{4}{|c|}{-49667.199} \\
\hline \multicolumn{5}{|c|}{ Likelihood ratio test: } & \multicolumn{4}{|c|}{46615.162} \\
\hline \multicolumn{5}{|c|}{ Rho-square: } & \multicolumn{4}{|c|}{0.319} \\
\hline \multirow{2}{*}{\multicolumn{5}{|c|}{ Activity Nest $\lambda$ value }} & \multicolumn{4}{|c|}{0.11} \\
\hline & & & & & \multicolumn{4}{|c|}{$(3.61)$} \\
\hline
\end{tabular}

Gender: male-1, female-0; Work: yes-1, no-0; No. of cars: number of cars in household; Age22_to_28: passenger age is between 22 and 28; Age_more_than_65: passenger age is over 65; No. of child: number of children in household; Logsum FromMainDest: log-sum from the main destination mode.

\subsection{Residential choice}

This model estimates the probability of the 149 zones in the Tel-Aviv metropolitan area being chosen as one's residential area. This is the same set of zones that serves as alternatives for the destination-choice model. It is the long-term decision model included in our study, in which we estimated the impact of activity/travel accessibility on the long-term decision of residential choice. In reality, decisions concerning the area in which one lives are limited to a defined set of alternatives, in which households consider a small number of options based on different constraints and preferences. The process of choosing a place to live, in other words, is usually thought of as being based on a two-stage choice process, by which the household first defines a small, relevant group of alternatives based on some preferences and constraints and then makes a final decision among these options. Such an approach was presented by Kaplan, Bekhor, and Shifton (2009, 2011). However, as mentioned, the complexity of the model created the need for simplification; hence, we simplified this choice by representing it as one stage of the full set of zones. This model includes various interaction variables, which are explained in Table 6 . 
Table 6: Residential choice variables

\begin{tabular}{|c|c|}
\hline Variable & Explanation \\
\hline HighPop_CarAvil & Number of cars in household if PopDensity $>11,000 / \mathrm{sq}-\mathrm{km}$ for each zone (1-149), 0 otherwise \\
\hline IsCBD & 1 if the zone is in the CBD, 0 otherwise \\
\hline IsCBD_CarAvil & Number of cars in household if the zone is in the CBD, 0 otherwise \\
\hline IsSec_NumChild & Number of children in household if the zone is in the 2nd ring, 0 otherwise \\
\hline BIsThird_CarAvil & Number of cars in household if the zone is in the 3 rd ring, 0 otherwise \\
\hline IsThird_IsWorker & 1 if the zone is in the 3 rd ring and the person is a worker, 0 otherwise \\
\hline IsThird_NumChild & Number of children in household if the zone is in the 3rd ring, 0 otherwise \\
\hline LowEmp_IsWorker & 1 if employment density $<3000 / \mathrm{sq}-\mathrm{km}$ in each zone and the person is a worker, 0 otherwise \\
\hline LowPop_NumChild & Number of children in household if PopDensity $>4000 / \mathrm{sq}-\mathrm{km}$ for each zone (1-149), 0 otherwise \\
\hline PopDens & Population density in each of the 149 zones \\
\hline Lnpop & Size variable, log of zone population \\
\hline log-sum FromMainAct & Log-sum from the Main Activity model \\
\hline
\end{tabular}

Equations 7-9 present the calculations of the main activity log-sum, and Table 7 gives the model estimation results. The distribution of the residential area shows that 4 percent live in the CBD, 34 percent in the second mantle, and 62 percent in the third mantle. The values in the table are parameter coefficients, and those in brackets are the t-test values.

The results show that as the family becomes larger with more children in the household, preferences are for less-dense zones, which are farther away from the center and are usually characterized by having larger apartments. Those areas, however, are less well served by public transit and, therefore, create the need for more cars per household; and, indeed, we do see households with more cars in less-dense areas. On the other hand, although the CBD is, in general, less attractive as a residential area, it becomes somewhat more attractive as the number of cars increases. This may be explained by the fact that apartments in the $\mathrm{CBD}$ are very expensive, thus attracting high-income people, who have more cars. In addition, the results indicate that areas in the outer ring are less likely to be chosen by workers, probably because of the distance from workplaces. Workers do tend to choose areas with low employment density, since they can probably afford them. The size variable, $\ln$ of the population, is significant, as it shows that larger zones are more likely to be chosen. Finally, the log-sum coefficient result clearly reveals the high influence of activity accessibility and of short-term opportunities and decisions (main mode, main destination, and main activity) on residential area choice. These results emphasize the importance of integrating the modeling of long-term lifestyles with daily activity and travel-choice models into one framework.

$$
\begin{gathered}
\text { Vactivity }=\frac{1}{\gamma} \operatorname{Ln}\left(e^{\text {Vwork }}+e^{\text {Vwork_r }}+e^{\text {Veducation }}+e^{\text {Vshopping }}+e^{\text {Vother }}\right) \\
\text { Vhome }=1 \\
\text { LogsumFromMainAct }=\operatorname{Ln}\left(e^{\text {Vactivity }}=e^{\text {Vhome }}\right)
\end{gathered}
$$


Table 7: Residential-choice model estimation results

\begin{tabular}{|c|c|c|}
\hline \multirow{2}{*}{ Variable } & \multicolumn{2}{|c|}{ Areas 1-149 } \\
\hline & $\beta$ value & t-test \\
\hline HighPop_CarAvil & -0.123 & $(-11.3)$ \\
\hline IsCBD & -0.259 & $(-7.64)$ \\
\hline IsCBD_CarAvil & 0.187 & $(6.87)$ \\
\hline IsSec_NumChild & 0.343 & $(7.57)$ \\
\hline IsThird_CarAvil & 0.118 & $(9.82)$ \\
\hline IsThird_IsWorker & -0.167 & $(-8.18)$ \\
\hline IsThird_NumChild & 0.399 & $(8.88)$ \\
\hline LowEmp_IsWorker & 0.039 & $(2.41)$ \\
\hline LowPop_NumChild & 0.182 & $(14.48)$ \\
\hline PopDens & 4.42E-06 & $(4.09)$ \\
\hline Lnpop & 0.913 & $(95.27)$ \\
\hline Log-sum FromMainAct & 0.637 & $(20.03)$ \\
\hline Number of estimated parameters: & \multicolumn{2}{|c|}{12} \\
\hline Number of observations: & \multicolumn{2}{|c|}{40717} \\
\hline Init log-likelihood: & \multicolumn{2}{|c|}{-203745.682} \\
\hline Final log-likelihood: & \multicolumn{2}{|c|}{-194520.963} \\
\hline Likelihood ratio test: & \multicolumn{2}{|c|}{18449.437} \\
\hline Rho-square: & \multicolumn{2}{|c|}{0.045} \\
\hline
\end{tabular}

\section{Conclusion}

The main objective of this research was to develop and demonstrate the use of ABA measures as a link between short-term activity and travel decision, on the one hand, and long-term decisions, such as residential choice, on the other. ABA can be very helpful in extending and integrating the general activitybased model framework to present the complex relationship between long-term individual decisions, such as residential location, and one's daily activity and travel behavior. Using ABA, we were able to show the impact of travel accessibility and short-term activity and travel decisions on activity participation and long-term decisions.

The basic assumption is that long-term mobility decisions, including residential location, affect the scheduling and allocation of activities and thus influence daily activity and travel patterns. Short-term decisions, such as mode used or main destination preference, can also lead to changes in long-term decisions. Hence, an extension of the methodological framework enables us to reach a better understanding of people's activity patterns and spatial decisions, which in turn can assist in better assessing the impact of transport and land-use policies on both types of decisions.

The present study, which used data from the Tel-Aviv activity-based model, included four models: main mode, main destination, main activity, and residential choice. The model system assumed some choice hierarchy, in which the longer-term choice of residence was highest on this ladder, followed in order by choice of activity participation, destination for this activity, and finally mode of travel to this activity. Although each decision is dependent on the one higher in the hierarchy, a full set of log-sums ensures that decisions at higher levels are also affected by the accessibility of lower-level decisions. All these log-sum variables were statistically significant. 
The log-sum variable from the main-mode-choice model in the destination-choice model shows that zones with more accessibility are more likely to be chosen as destinations for activities. The destination-choice log-sum in the main-activity model reveals that people are more likely to participate in out-of-home activities as accessibility increases. This finding presents one of the main advantages of activity-based models, in which the generation of activities and the trips conducted to participate in these activities are not fixed; rather, they depend on accessibility — that is, on transport investments and policies.

The highly significant activity-choice log-sum in the residential-choice model, the long-term element in our study, clearly shows the large influence of activity accessibility and short-term opportunities and decisions (main mode, main destination, and main activity) on residential area choice. This result emphasizes the importance of integrating the modeling of long-term lifestyles with daily activity and travel-choice models into one framework. Other results of the residential-choice model show that as the family becomes larger, the household's preferences or constraints lead to the selection of less-dense zones, which are farther away from the center. Interestingly, when there are more cars in the household, the $\mathrm{CBD}$ becomes somewhat more attractive, a phenomenon, as explained in the results section, that might be connected to attracting car-owning, high-income individuals.

From a policy point of view, these results of the relationship between residential location decisions and daily activity patterns emphasize the Tel-Aviv metropolitan area's problematic general land-use distributions, which are commonly characterized by distinct employment areas and separated housing areas. This troubling situation is clear from different model results, such as the "conflict" between family size, which leads to opting for areas farther from the $\mathrm{CBD}$ owing to the need for larger dwellings, and limited appropriate residence availability in the center, on the one hand, and workers' preference not to live in the third ring so as to avoid too long a commute, on the other hand. This separation in housing and working areas leads, in addition, to choosing the car mode for traveling to activities.

The division of land uses, which is now known to be destructive, is changing in many western cities. Areas are becoming more mixed use, with housing, shopping, offices, and leisure facilities all integrated into the area. The results of this study indicate that municipalities would do well to implement mixed-use zoning policies. Such policies may offer, within a short riding distance, a high density of employment and dwelling options that combine housing, shopping, and office land uses in an attractive area for both living and working. The conclusion reached by Lee et al. (2010), one that coincides with the current study, is that relaxation of land-use regulations from mostly single-use zoning to a more mixed-use zoning is recommended, as individuals and households place high value on access to jobs and various activities, such as shopping and dining. Indeed, a significant percentage of the population travels in multi-segmented tours, with multiple destinations.

Our research results also point out the need to make public transportation more attractive in terms of time, price, and frequency to attract users who have other transportation-mode options. Public transportation improvement should be guided by clear planning policies that include road-use priority, increased frequencies, and better connectivity between different lines and different public transportation modes. These two elements, land-use mixture and improvement in public transportation, are key aspects in changing people's activity patterns so that the built environment will fit the respondents' preferences as was indicated by the short-term and long-term decisions included in this study.

Current activity-based models usually lack a full set of log-sum variables that try to make these models simpler and more applicable. This study shows the importance of including such variables and carrying them over to longer-term decisions, such as residential choices. Future research should find ways to simplify the inclusion of log-sum variables in full activity-based models so as to make it easier to integrate short-, medium-, and long-term decisions into one framework. With such integrated models, 
it would be much less time consuming and cumbersome to model the interrelationships of various decisions concerning travel, activity, and longer-term mobility. The model presented here provides a starting point for further development of long-term decision models, including ABA measures, and for testing the applicability and contribution of the current framework to better policy analysis. Much more work needs to be done to properly account for all the behavioral complexities involved in both short-term and long-term decisions. To develop and implement such a framework, future research needs to address such issues as the structure (order) of the various sub-models; the dynamic of changes over time and circumstances; the residential location-choice process, which is usually considered a two-stage process (Kaplan, Bekhor, and Shiftan 2009, 2011); and the correlations between different zones and various constraints. Finally, model validation should be part of the planning process.

\section{References}

Algers, S., and M. Beser. 2000. SAMPERS—The new Swedish national travel demand forecasting tool, paper presented at IATBR 2000 Conference, June 2000, Gold Coast, Australia.

Aretze, T. A., and H. J. P. Timmermans. 2000. Albatross: A Learning-Based Transportation Oriented Simulation System. Eindhoven, The Netherlands: Euro Inst Ret Serv Stud.

Arentze, T. A., and H. P. Timmermans. 2004. A micro-simulator of urban land-use dynamics integrating a multi-agent model of land development and an activity-based model of transport demand, Proceedings of the 83rd Annual Meeting of the Transportation Research Board, January 11-15, Washington, DC (CD-Rom).

Boarnet, M. G., and S. Sarmineto. 1998. Can land-use policy really affect behavior? Urban Studies N 35(7): 1155-1169.

Badoe, D. A., and E. J. Miller. 2000. Transportation-land-use interaction: Empirical findings in North America, their implications for modeling. Transportation Research D 5(4): 235-263.

Bagley, M. N., and P. L. Mokhtarian. 2000. The impact of residential neighborhood type on travel behavior: A structural equations modeling approach, The XI Pan-American Conference of Traffic Transportation Engineering, Gramado, Brazil.

Ben-Akiva, M., and J. L. Bowman. 1998. Integration of an activity-based model system and a residential location model. Urban Studies 35(7): 1131-1153.

Blijie, B. 2005. The impact of accessibility on residential choice-Empirical results of a discrete choice model, 45th Cong European Regional Science Association, August 23-27, 2005, Amsterdam. http://www-sre.wu-wien.ac.at/ersa/ersaconfs/ersa05/papers/626.pdf; http://ideas.repec.org/p/wiw/ wiwrsa/ersa05p626.html

Bowman, J. L., and M. Bradley. 2006. Disaggregate treatment of purpose, time of day, and location in activity-based regional travel forecasting models, European Transport Conference, September 18-20, Strasburg, France.

Bowmam, J., M. Bradley, Y. Shiftan, T. K. Lawton, and M. Ben-Akiva. 1998. Demonstration of an activity based model system for Portland, 8th World Confernce on Transportation Research, July 12-16, Antwerp, Belgium.

Bradley, M., M. Outwater, N. Jonnalagadda, and E. Ruiter. 2002. Estimation of an activity-based micro simulation model for San Francisco, 81st Annual Meeting of the Transportation Research Board, June 13-17, Washington, DC.

Bradly, M., and P. Vovsha. 2005. A model for joint choice of daily activity pattern types of household members. Transportation 32(5): 545-571.

Cervero, R. 1989. America's Suburban Centers: The Land Use-Transportation Link. London: Allen and 
Unwin.

Cervero, R., and K. Kockelman. 1997. Travel demand and the 3Ds: Density, diversity, and design. Transportation Research Part D 2(3): 199-219.

Crane, R., and R. Crepeau. 1998. Does neighborhood design influence travel? A behavioral analysis of travel diary and GIS data. Transportation Research Part D 3: 225-238.

Dong, X., M. E. Ben-Akiva, J. L. Bowman, and J. L. Walker. 2006. Moving from trip-based to activity-based measures of accessibility. Transportation Research Part A 40(2): 118-130.

Dunphy, R., and K. Fisher. 1996. Transportation, congestion, and density: New insight. Transportation Research Record 1552: 89-96.

Ettema, D., K. de Jong, H. Timmermans, and A. Bakema. 2006. PUMA: Multi-agent modeling of urban systems. Washington, DC: Transportation Research Board (CD-ROM).

Frank, L., and G. Pivo. 1994. Impact of mixed use and density on utilization of three models of travel: Single-occupant vehicle, transit, and walking. Transportation Research Record 1466: 44-52.

Gunn, H. F., and A. Van der Hoorn. 1998. The predictive power of operational demand models, Proceedings of Transportation Planning Methods seminar, London.

Handy, S. 1996. Understanding the link between urban form and nonwork travel behavior. Journal of Planning Education Research Part N15(3): 183-198.

Hatzopoulou, M., and E. J. Miller. 2009. Transport policy evaluation in metropolitan areas: The role of modeling in decision-making. Transportation Research Part A 43(4): 323-338.

Holtzclaw, J. 1990. Manhattanization versus sprawl: Low density impacts auto use comparing five Bay area communities. Proceedings of the 11th International Pedestrian Conference, Boulder, CO.

Jonnalagadda N., J. Freedman, W. Davidson, and J. D. Hunt. 1999. Development of a microsimulation activity-based model for San Francisco-Destination and mode choice models. Transportation Research Record 1777: 25-35.

Kaplan, K., S. Bekhor, and Y. Shiftan. 2009. A two-stage model jointly revealing the determinants of non-compensatory conjunctive choice set information and compensatory choice, Proceedings of the 88th Annual Meeting of the Transportation Research Board, January 11-15, Washington, DC (CDRom).

Kaplan, K., S. Bekhor, and Y. Shiftan. 2011. Eliciting and estimating reservation price: A semi-compensatory approach. Journal of Business Research 64(1): 45-60.

Katoshevski-Cavari, R. 2007. A multi-agent planning support system for assessing externalities of urban form scenarios; development and application in an Israeli case study. PhD Dissertation. Eindhoven, The Netherlands: Eindhoven University Press.

Katoshevski-Cavari, R., T. Arentze, and H. Timmermans. 2009. A computerized tailor-made planCan that be a tool for achieving public interest in planning? Geography Research Forum 29: 26-47.

Kitamura, R., P. Mokhtarian, and L. Laidet. 1997. A micro-analysis of land-use and travel in five neighborhoods in the San Francesco Bay area. Transportation 24(2): 125-128.

Kitamura, R., E. L. Pas, C. V. Lula, T. K. Lawton, P. Benson, and M. Ben-Akiva. 1996. The sequenced activity mobility simulator (SAMS): An integrated approach to modeling transportation, land-use, and air quality. Transportation 23(3): 267-291.

Lee, B., P. Waddell, L. Wang, and R. M. Pendyala. 2010. Reexamining the influence of work and nonwork accessibility on residential location with a microanalytic framework. Environment and Planning A 42: 913-930.

Miller, E. J., J. D. Hunt, J. E. Abraham, and P. A. Salvini. 2004. Microsimulation urban systems. Computer Environment and Urban Systems 28: 9-44.

Miller, E. J. 2005. An integrated framework for modeling short and long-run household decision- 
making, in Progress in Activity-based Analysis, edited by H. Timmermans. Amsterdam: Elsevier.

Newman, P., and J. Kenworthy, J. 1989. Gasoline consumption and cities: A comparison of US cities with a global survey. Journal of the American Planning Association 55(1): 24-37.

Newman, P., and J. Kenworthy. 1999. The Cost of Automobile Dependence: A Global Survey of Cities. Washington, DC: Transportation Research Board.

Pendyala, R., R. Kitamura, and A. Kikuchi. 2004. FAMOS: The Florida Activity Mobility Simulator, Conference on Progress in Activity-Based Analysis, May 28-31, 2004, Maastricht, The Netherlands.

Roorda, M.J., J. A. Carrasco, and E. J. Miller. 2009. An integrated model of vehicle transactions, activity scheduling, and mode choice. Transportation Research Part B 43: 217-229.

Roorda, M. J., and T. Ruiz. 2008. Long- and short-term dynamics in activity scheduling: A structural equations approach. Transportation Research Part A 42(3): 545-562.

Rossi, T., and Y. Shiftan. 1997. Tour-based travel demand modeling in the U.S., Proceedings of the 8th IFAC/IFIP/IFORS Symposium on Transportation Systems, June 16-18, Chania, Greece.

Salvini, P., and E. J. Miller. 2005. ILUTE: An operational prototype of a comprehensive microsimulation model of urban systems. Networks and Spatial Economics 5: 217-234.

Shiftan, Y. 1999. A practical approach to model trip chaining. Transportation Research Record 1945: $17-23$.

Shiftan, Y. 2008. The use of activity-based modeling to analyze the effect of land-use policies on travel behavior. Annals of Regional Science 42: 79-97.

Shiftan, Y., and M. Ben-Akiva. 2011. A practical policy-sensitive, activity-based, travel demand model. Annals of Regional Science 47(3): 517-541.

Shiftan, Y., and J. Suhrbier. 2002. The analysis of travel and emission impacts of travel demand management strategies using activity-based models. Transportation 29(2): 145-168.

Van Acker, V., and F. Witlox. 2010. Car ownership as a mediating variable in car travel behavior research using a structural equation modeling approach to identify its dual relationship. Journal of Transportation Geography 18(1): 65-74.

Waddell, P. 1996. Accessibility and residential location: The interaction of workplace, residential mobility, tenure, and location choices, Paper presented at the 1996 Lincoln Institute of Land Policy Taxation Resources and Economic Development Conference on Transportation and Land Use, October 1996, Cambridge, MA. http://oregon.gov/ODOT/TD/TP/docs/TMR/UrbanSim/tred96b.pdf

Weisbrod, G. E., S. R. Lerman, and M. E. Ben-Akiva. 1980. Tradeoffs in residential location decisions: Transportation versus other factors. Transportation Policy and Decision Making 1: 13-26.

Yagi, S. 2006. An activity-based microsimulation model of travel demand in the Jakarta metropolitan area, 11th International Conference on Travel Behavior Research, August 16-20, Kyoto, Japan.

Zondag, B., and M. Pieters. 2005. Influence of accessibility on residential location choice. Transportation Research Record 1902: 63-70. 